Article

\title{
Vinculum of Sustainable Development Goal Practices and Firms' Financial Performance: A Moderation Role of Green Innovation
}

\author{
Parvez Alam Khan ${ }^{1}{ }^{\mathbb{B}}$, Satirenjit Kaur Johl ${ }^{1, *}$ and Shakeb Akhtar ${ }^{2}$ \\ 1 Department of Management and Humanities, Universiti Teknologi PETRONAS, \\ Seri Iskandar 32610, Perak, Malaysia; parvezkhan.alam@gmail.com \\ 2 Department of Finance, School of Business, Galgotias University, Greater Noida 203201, Uttar Pradesh, India; \\ shakebakhtar.amu@gmail.com \\ * Correspondence: satire@utp.edu.my
}

check for updates

Citation: Khan, Parvez Alam, Satirenjit Kaur Johl, and Shakeb Akhtar. 2022. Vinculum of Sustainable Development Goal Practices and Firms' Financial Performance: A Moderation Role of Green Innovation. Journal of Risk and Financial Management 15: 96. https://doi.org/10.3390/jrfm 15030096

Academic Editor: Thanasis Stengos

Received: 17 November 2021

Accepted: 28 December 2021

Published: 22 February 2022

Publisher's Note: MDPI stays neutral with regard to jurisdictional claims in published maps and institutional affiliations.

Copyright: (C) 2022 by the authors. Licensee MDPI, Basel, Switzerland. This article is an open access article distributed under the terms and conditions of the Creative Commons Attribution (CC BY) license (https:// creativecommons.org/licenses/by/ $4.0 /)$.

\begin{abstract}
The 2030 Agenda for Sustainable Development (SDGs) has been established to alter our world by addressing the challenges faced by humanity in order to promote wellbeing, economic prosperity, and the protection of the environment. The SDGs provide a holistic and multi-dimensional approach to development compared to conventional development plans that focus on a limited range of dimensions. As a result, linkages between the SDGs may result in differing outcomes. This research is the first to investigate the direct relationship of environmental and social SDGs with firms' financial performance and the moderating role of green innovation. Data from 67 companies from five continents (Europe, Australia and New Zealand, Asia, North America, and Africa) and their top five blue-chip firms were collected through content analysis. Generalized least squares (GLS) were used to test for direct relationships. The results showed a positive correlation between environmental SDGs and the negative significance of social SDGs on firms' financial performance. However, mixed findings regarding the moderation variable green innovation over SDGs and firms' financial performance were found. The new findings extend the SDG literature and provide empirical evidence to practitioners and policymakers.
\end{abstract}

Keywords: green innovation; sustainable development goal; environmental policy; financial performance; environment and social

\section{Introduction}

The COVID-19 pandemic has become the greatest threat to humanity since the 1918 influenza pandemic (Akhtar et al. 2020). This pandemic also poses a massive obstacle to achieving the United Nation's sustainable development goals (SDGs) (Wang and Huang 2021); however, the world has also experienced a reduction in greenhouse gases (Stoll and Mehling 2020), waste generation, and other environmental challenges during the COVID-19 pandemic, but this is expected to rise at double the rate as the pandemic transitions to an endemic status. Sustainable practices and responsible investment have also been given significant attention over the last few decades (Sciarelli et al. 2021; Wahab and Naim 2021). This gesticulation has been intensified due to global commitments towards curbing greenhouse gases, waste generation, water contamination, and rethinking resource scarcity (Stoddard et al. 2021).

The motivation of this study is the rise in both responsible investment and environmental problems that have raised concerns amongst researchers, and also towards investors and policymakers. In addition, these challenges are also becoming a hurdle for achieving sustainable development (Ogunbiyi et al. 2014). The term "sustainable development" (SD) was first defined as "the development that meets the needs of the present without compromising the ability of future generations to meet their own needs", found in the 
document "Our Common Future", by the United Nations Commission on Environment and Development (Brundtland Commission) (Jan et al. 2021c). SD aims to address humanity's aspirations for a better life within the limitations imposed by nature. The United Nations' 17 SDGs are an urgent call to action for all nations (Mio et al. 2020), delivering a universal framework for accomplishing global development while harmonizing societal, economic, and environmental sustainability. The SDGs present a holistic and multifaceted vision of development; the holistic nature of the SDG framework compels policymakers to assess several potential linkages among the 169 targets (Costanza et al. 2016; Rickels et al. 2016).

The exiting literature on SDGs is currently being investigated in terms of the adoption by larger firms (Santos and Bastos 2020), scalable solutions to SDGs through social entrepreneurship (Goyal et al. 2020), the role of ISO (Khan et al. 2021d), environmental policy (Coscieme et al. 2021), the implication of SDGs' sustainable reporting (Calabrese et al. 2021), and firms' contributions through community partnerships over SDGs with major positive outcomes (Ordonez-Ponce et al. 2021). Additionally, the literature has also reported the investigation of IoTs such as digital sustainability contribution (Ribeiro et al. 2021), digitalization and integration (Onyango and Ondiek 2021), Big Data (Hassani et al. 2021), and blockchain (Parmentola et al. 2021), in promoting the sustainable development goal within firms. The findings in the literature, at the country level, also indicate the significant positive relationship amongst SDGs (Pradhan et al. 2017). However, there are limited firm-level studies that intend to investigate firms' return on SGD practices.

In addition, the global ecological crisis includes the scarcity of resources, environmental degradation, and pollution, which has compelled countries to prioritize sustainable development (Cai et al. 2018). Likely to mitigate these environmental challenges, green innovation/environmental innovation has been projected and positively reported without affecting firms' financial performance. Innovation is also seen as a major source for creating a competitive edge for firms (Cai et al. 2018), which is triggered by innovating products, processes, and services aiming to limit resource consumption that impacts the environment, achieving sustainability (Baloch et al. 2021).

In most green innovation studies, the authors (Tariq et al. 2017; Albort-Morant et al. 2016) argued that capital investment is required if businesses decide to implement green innovation and green practices (Zhang et al. 2020b) and that they gain an opportunity to strengthen their competitive advantage (Ho et al. 2016), while also enjoying several advantages, including creating goodwill (Khan et al. 2021e; Lin et al. 2021) and shareholder trust and attracting premium pricing (Zhang and Ma 2021), particularly if the firm is the instigator (Khan et al. 2021d). Zhang (Zhang et al. 2020c) stated that a firm's effective and efficient performance and profitability could be achieved by implementing green innovation. Moreover, some authors (Aastvedt et al. 2021; Khan et al. 2021d; Wang et al. 2021) found that GI is inextricably related to an organization's competitive advantage and is more successful at engaging both key stakeholders; additionally, green innovation reflects the vision, goals, and eco-consciousness of employees at all levels of management.

This study intends to examine two objectives. First, the moderating role of green innovation over the environmental, socially sustainable development goals, and firms' financial performance; secondly, the effect of sustainable development goal practices over firms' financial performance amongst blue-chip companies across five continents. This research gap can also be identified from the literature, stated in Table 1, below. 
Table 1. Related Literature-Identifying Research Gap.

\begin{tabular}{|c|c|c|c|c|}
\hline Independent Variable & Dependent Variable & Findings & Reference & Remark \\
\hline Green innovation & $\begin{array}{c}\text { Sustainable } \\
\text { development goals }\end{array}$ & $\begin{array}{l}\text { Green innovation has had a positive } \\
\text { impact on the sustainable development } \\
\text { goals, community engagement, and } \\
\text { improvement of the environment. The } \\
\text { backing of the government greatly } \\
\text { strengthens green innovation and } \\
\text { environmentally sound activities. }\end{array}$ & (Ullah et al. 2021) & Positive \\
\hline $\begin{array}{l}\text { Green Innovation } \\
\text { reporting }\end{array}$ & $\begin{array}{c}\text { Sustainable } \\
\text { development goals }\end{array}$ & $\begin{array}{c}\text { Adopting an ISO 56002-2019 innovation } \\
\text { management system has helped } \\
\text { companies achieve sustainable } \\
\text { development goals. }\end{array}$ & (Khan et al. 2021d) & Positive \\
\hline $\begin{array}{c}\text { Sustainable } \\
\text { development goals }\end{array}$ & $\begin{array}{l}\text { Financial performance } \\
\text { (return on equity) }\end{array}$ & $\begin{array}{l}\text { The results suggest that firms without } \\
\text { SDGs have traditionally achieved better } \\
\text { FP (i.e., higher ROE). Consequently, the } \\
\text { incorporation of SDGs in their strategy } \\
\text { leads to a lower ROE. }\end{array}$ & (Lassala et al. 2021) & Negative \\
\hline $\begin{array}{c}\text { Sustainable } \\
\text { development goals }\end{array}$ & $\begin{array}{l}\text { ESG sustainability } \\
\text { practices }\end{array}$ & $\begin{array}{l}\text { The mapping can be used to help } \\
\text { comprehend the connections amongst } \\
\text { ESG issues, corporate sustainability } \\
\text { performance, and the SDGs, as well as } \\
\text { to quantify organizations' progress } \\
\text { towards the achievement of SDGs. }\end{array}$ & (Khaled et al. 2021) & Positive \\
\hline Innovation & $\begin{array}{c}\text { Sustainable } \\
\text { development goals }\end{array}$ & $\begin{array}{l}\text { The results demonstrate that the } \\
\text { intensity of cooperative integration, } \\
\text { diversification within the organization, } \\
\text { market orientation, and achieving } \\
\text { Sustainable Development Goals favors } \\
\text { the degree of technical innovation. }\end{array}$ & $\begin{array}{l}\text { (Mozas-Moral et al. } \\
\text { 2020) }\end{array}$ & Positive \\
\hline
\end{tabular}

The recent literature in Table 1 shows that two studies have investigated the negative relationship between SDGs, firms' financial performance (Parmentola et al. 2021), and positive firms' non-financial performance (Khaled et al. 2021). On the other hand, the literature contains several studies investigating green innovation on firms' financial performance (Khan and Johl 2020; Tjahjadi et al. 2020; Zhang et al. 2019, 2020a; Tang et al. 2018) firms' values (Asni and Agustia 2021), and firms' risk (Lin et al. 2020). However, to the best of the authors' knowledge, only two studies have investigated the relationship of green innovation and SDGs (Ullah et al. 2021; Khan et al. 2021d) with positive outcomes. Maintaining this prospect, this research addresses the inconclusive limited literature by investigating the relationship between SDG practices and firms' financial performance. Moreover, to the best of the authors' knowledge, no study has investigated the moderating role of green innovation, as green innovation can significantly address sustainability issues, particularly the environment.

Therefore, this is the first study that explores the moderating role of green innovation practices in firms over sustainable development goal practices and their effect on the financial performance of firms. To conduct this research, this study has investigated the topfive countries (based on the GDPs of every continent) and their blue-chip companies (based on the market capital). In total, 67 firms' data were collected for the final data analysis from each company's website for the years 2018 and 2019, totalling 134 observations.

This study offers three main contributions. First, this research is amongst the earliest investigations of the direct relationship of SDG practices over firms' financial performance with a significantly positive relationship. These findings support the aim of creating a collective approach within the United Nations. Secondly, these findings also show the positive return on assets and the return on equity over SDG practices, which shows the 
management efficiency of the firms and attracts sustainably responsible investors. Thirdly, the moderation of green innovation practices over the SDG practices and firms' performance showed significant mixed findings due to the short period of time (2018-2019); however, the research in the literature reported a positive significance and created a competitive advantage for firms in the long run (Kim et al. 2021; Zhang et al. 2020c).

The discussion of this paper flows in five sections. Section 2 highlights each variable in the literature, followed by Section 3, which lays out the data methodology. Section 4 expounds the results and the discussion, followed by Section 5, which discusses the implications and conclusion of the study.

\section{Literature Review and Conceptual Framework Development}

Aiming at this research objective, and at two imperative gaps that have been drawn from the literature, this section will bring a greater rationale from the existing literature to strengthen our research. The literature review covers the sustainable development goals as independent variables and firms' financial performance as the dependent variable. In contrast, green innovation is the moderating variable of this study. Moreover, the study measures the outcome through two well-established accounting ratios that depict the management efficiency, cover investors (R.O.E.), and firms' (ROA) prospects.

\subsection{Firms' Financial Performance}

As mentioned above, the dependent variable of this research is the firms' financial performance, which must be measured through the return on assets (ROA) (Akhtar et al. 2020; Chaturvedi et al. 2021), return on equity (ROE) (Yi et al. 2021) (both ratios measure firms' management efficiency concerning shareholder equity (ROE) (Jan et al. 2019a; Muhammad Zahid et al. 2020), and asset utilization (ROA). These accounting ratios were also chosen due to their wide adoption in the existing literature to assess the effect of sustainability (Hussain et al. 2018; Nguyen et al. 2021), green innovation (Xu et al. 2021; Yi et al. 2021), eco-innovation (Johl and Toha 2021; González-Ruiz et al. 2018; Sharif and Alhiyasat 2018), sustainable practices (Jan et al. 2021a, 2021b), and the inclusion of intellectual capital into the green board (Shah et al. 2021) on a firm's balance sheet-these accounting ratios also help investors predict a firm's expected profitability, financial stability before the investment and firm bottom line (Ahmad et al. 2021; Jan and Marimuthu 2015; Jan et al. 2018, 2019b).

In addition, there are also non-financial parameters; for instance, ESG (Fatemi et al. 2018), operational performance (Inman and Green 2018), and sustainable development goals (Hussain et al. 2018); however, this study adopts only the firms' financial performance due to the research objective and the research gap impacting SDGs to firms financial performance.

The SDG practices are investigated at the country level, with a positive relationship amongst the SDGs which outweighs the negative effects in most economies; this implies that the countries are positively adopting and implementing the SDGs and their associated agenda (Pradhan et al. 2017). The author has reported the findings and found that Finland, Germany, and Japan ranked first amongst the investigated countries (Pradhan et al. 2017).

This study also measures the SDG practices at the larger-firm level (blue-chip firms), as no studies have investigated the correlation between SDG practices and accounting ratios (ROA and ROE). Therefore, this study has also adopted both accounting ratios to measure the effect of sustainable development goal practices on firms' financial performance and the moderating role of green innovation. This vinculum of both variables (SDG and firms' financial performance) is discussed in the following section.

\subsection{Nexus of Sustainable Development Goals Practice and Firms' Financial Performance}

We have initiated the literature search by exploring Scopus data based on the combination of the keywords "Sustainable development Goals" and "Firm Performance", and found only 20 studies (Appendix A-Table A1). For instance, the existing literature on 
SDGs is investigating factors that increase SDG practices (Santos and Bastos 2020); for instance, scalable solutions to SDGs through social entrepreneurship (Goyal et al. 2020), the role of ISO (Khan et al. 2021d; Toha et al. 2020), environmental policy (Coscieme et al. 2021), the implication of SDGs' sustainable reporting (Calabrese et al. 2021), and firms' contribution through community partnerships over SDGs have been studied, with a majority of positive outcomes (Ordonez-Ponce et al. 2021). The literature also contains studies that have investigated the effect of the industrial revolution on IoTs such as digital sustainability contribution (Ribeiro et al. 2021), digitalization and integration (Onyango and Ondiek 2021), Big Data (Hassani et al. 2021), and blockchain (Parmentola et al. 2021) in promoting sustainable development goals amongst firms. In addition, the literature also shows data at the country level and indicates a significant positive relationship amongst SDGs (Pradhan et al. 2017).

However, no research has investigated what firms receive in return for SGD practices. Therefore, this study categorized 17 SDGs into two main pillars of sustainability: (1) environmental and (2) social SDGs (Dalampira and Nastis 2020), which depict the practices and contributions towards sustainable development goals and sustainability. Mapping a business' operational and non-operational activities to the 17 SDGs will also improve a firm's sustainability and contribute directly to Decent Work and Economic Growth (SDG 8); Industry, Innovation, and Infrastructure (SDG 9); Responsible Consumption and Production (SDG 12); and Climate Action (SDG 13) (Ullah et al. 2021) through a business' operational activities, and indirectly to other SDGs such as Promote Peaceful and Inclusive Societies (SDG 16), and Life on a Sustainable Planet (SDG 17, SDG 3).

Moreover, there is also discussion on the 18th SDG, regarding animal health, welfare, and rights, which the United Nations has neglected; however, it has yet to be established (Visseren-Hamakers 2020). Therefore, this research considers all 17 SGDs. This vinculum of sustainable development goals with firms' financial performance is limited in the existing literature. However, in Lassala et al. (2021), the author found that sustainable initiatives/behaviours vary amongst firms, and the effect on the firms' financial performance varies and addresses a wide range of stakeholders.

In Lassala et al. (2021), the author also advocated that firms follow a proactive approach to reduce costs and minimize risks, minimizing the effect on society and helping in the shift towards society 5.0. The following literature section will discuss the correlation of social SDGs with firms' financial performance, as shown in Figure 1, below.

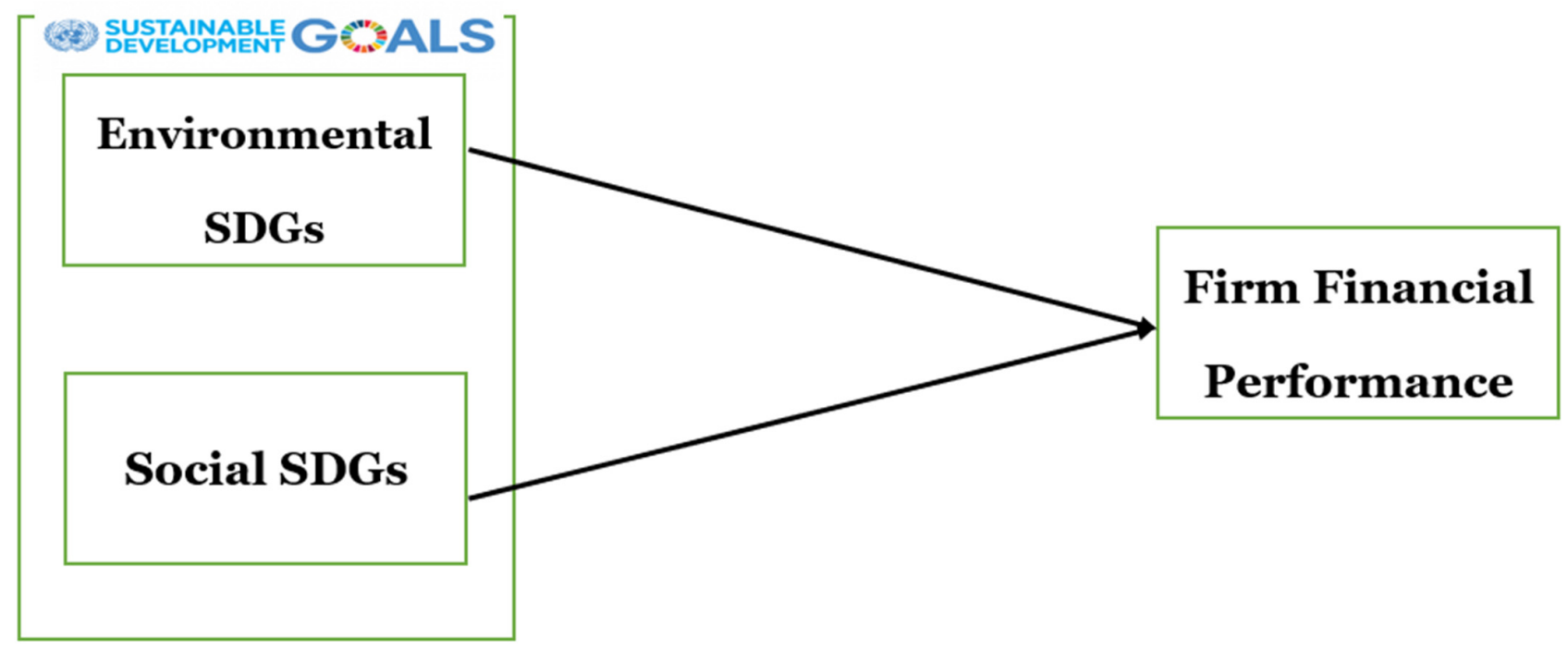

Figure 1. SDGs and firms' financial performance. 


\subsubsection{Environment SDGs}

In the current industrial revolution (IR4.0), environmental reporting and corporate initiatives minimize the burden of the environmental drive awareness amongst other related stakeholders. On the other hand, policymakers have also strengthened the effect of initiatives by implementing policies to save the environment and society (Jan et al. 2019a). Likewise, policymakers have enacted mandatory sustainable reporting and integrating reporting, obliging companies to report their operational business actives in annual reports (Hamad et al. 2020). Next, the environmental disclosure level increased significantly from 2005 to 2018. Moreover, there is exemplary reporting of environment data disclosure (up to $90-100 \%$ ) within companies' GRI reports. Environmental disclosure can be viewed in sustainability reports, and global reporting initiatives (GRI) in recording and reporting the quality information of the environment, including emissions, waste, water consumption, energy use, environmental incidents, and fines.

These enormous environmental challenges have raised concern during the end of the third industrial revolution. The current industrial revolution (IR 4.0) has introduced solutions to capture and utilize greenhouse gases from the environment (Yusuf et al. 2021b). Secondly, fossil fuels are accelerating global warming, and dealing with hydrogen-fueled energy is a promising alternative for providing cleaner energy while controlling the rise in global temperatures (Yusuf et al. 2021a).

Furthermore, in 2015, the United Nations created a further 17 sustainable development goals to formulate a collective approach to deal with major challenges regarding the environment and society. This study proposes seven sustainable development goals (SDGs) as environmentally sustainable development goals (SDGs); these nine SDGs are partnership (SDG 17), life on land (SDG 15), life below water (SDG 14), climate change (SDG 13), responsible production (SDG 12), clean energy (SDG 7), SDG 7 renewable energy, SDG 9 innovation and infrastructure, and clean water (SDG 6). The literature also proposes six transformations to achieve the SDGs: education, gender inequality, health, sustainable industry, sustainable food, land, water and oceans, sustainable communities, and the digital revolution (Sachs et al. 2019). These six transformations require the attention of stakeholders, as each transformation identifies priority investments and regulatory challenges. However, the situation remains the same by targeting six transformations or 17 SDGs, since it requires an equal level of awareness, initiative, and investment from stakeholders to achieve the SDGs.

These nine SDGs are classified within the environmental SDGs, as their focus is on the environment. Therefore, due to the limited studies on measuring ecological SDG on firms ${ }^{\prime}$ financial performance, the following hypotheses have been formulated:

Hypothesis 1a (H1a). Sustainable development goal (environmental) has a significant positive relationship with firms' financial performance (ROA).

Hypothesis $\mathbf{1 b}$ (H1b). Sustainable development goal (environmental) has a significant positive relationship with firms' financial performance (ROE).

\subsubsection{Social SDGs}

This study classified 17 SDGs, mainly the above-mentioned environmental and socially sustainable development goals. Socially sustainable development goals (SSDGs) include: (SDG 1) no poverty, (SDG 2) zero hunger, (SDG 3) good health, (SDG 4) quality education, (SDG 5) gender equality, (SDG 8) good jobs and economic growth, (SDG 16) peace and justice, and (SDG 17) partnership for the goals (Appendix A-Table A1).

In the last ten years, out of the eight mentioned SDGs, few have been seen in companies' reports as part of ESG reporting. In the social reporting of ESG, companies' focus was mainly limited to internal social practices. The limitation of the social practices of ESG can be eliminated through the adoption of socially sustainable development goals. 
Socially sustainable development goals (social SDGs) are creating urgent challenges that society is facing and that need to be addressed by the government, companies, and all individuals across the world. In Rosati and Faria (2019), the authors stated that businesses could boost sustainable development goals by implementing them into their business activities. The authors also claimed that the disclosure of the SDGs can enhance business planning, implementing, and monitoring activities, as well as the communication with stakeholders.

Moreover, social SDGs have the ability to impact a firm's financial statement, and various researchers have reported findings, in the ESG literature, on the effect of social SDGs on firms' financial performance; however, these eight SDGs focus on societal development, and this study is amongst an early study to conduct a correlation analysis between social SDGs on firms' financial performance. Therefore the following hypotheses are formulated:

Hypothesis 2a (H2a). Sustainable development goal (social) has a significant positive relationship with firms0 financial performance (ROA).

Hypothesis $\mathbf{2 b} \mathbf{( H 2 b ) . ~ S u s t a i n a b l e ~ d e v e l o p m e n t ~ g o a l ~ ( s o c i a l ) ~ h a s ~ a ~ s i g n i f i c a n t ~ p o s i t i v e ~ r e l a t i o n s h i p ~}$ with firms' financial performance (ROE).

\subsection{Green Innovation Practice-Moderation Variable}

Green innovation is the modification and introduction of a different product, process, and/or service which further minimizes the emissions and input towards green ecology (Calza et al. 2017). Green operational innovation is defined as an innovation that enhances an organization's efficiency related to business operation activities; business operational efficiency can be achieved through green innovation through a business's product, process, and/or service. A brief outline in shown in Figure 2.

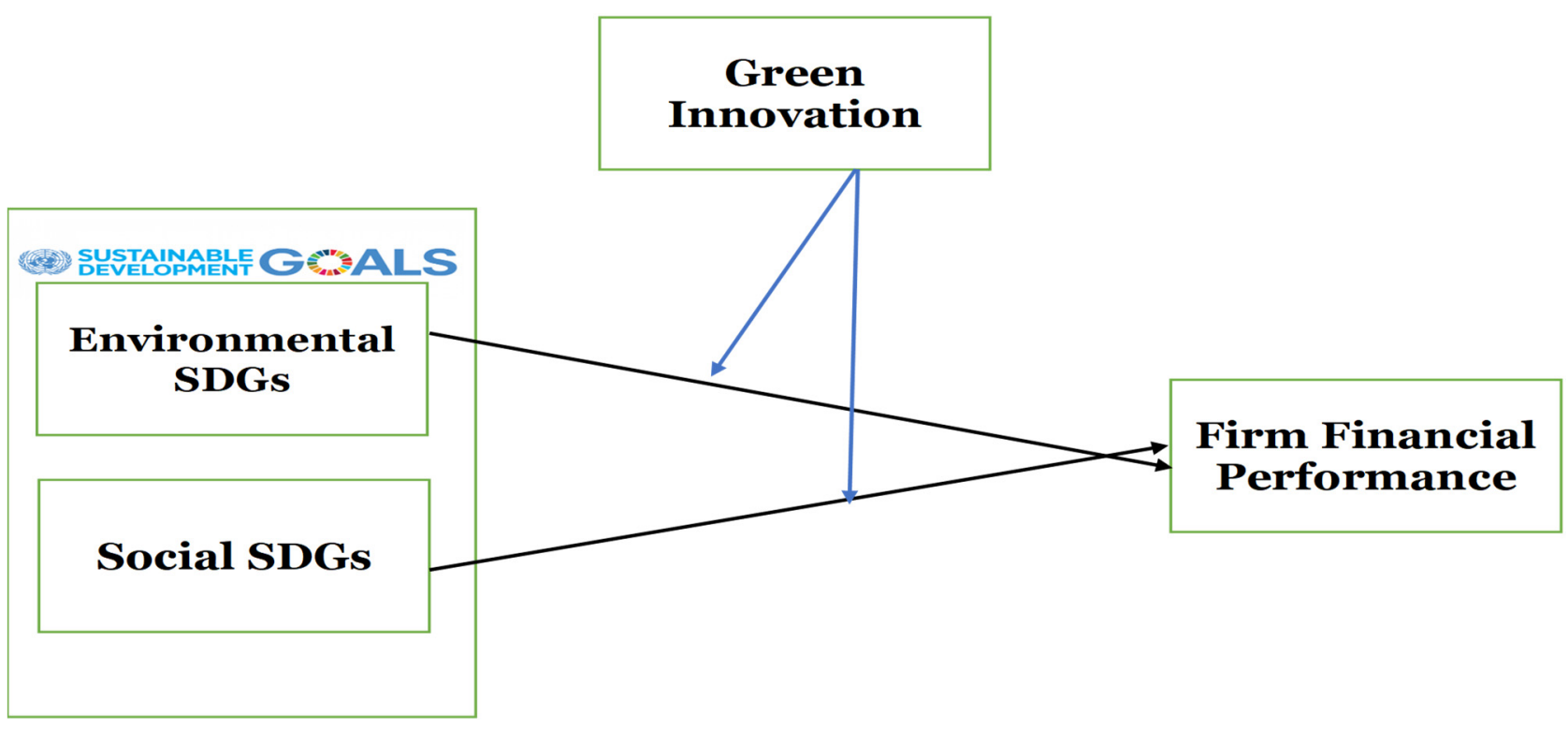

Figure 2. Moderation: Green innovation over SDGs and firms' financial performance.

The current literature on green innovation has a different synonym: ecological, environmental, and eco-innovation are used by various researchers (Costanza et al. 2016) to integrate - in different contexts_-performance measurement criteria. Ultimately, most research findings suggest that green innovation decreases the environmental burden, creating value for related stakeholders and strengthening business activities.

The literature on green innovation has evolved in the current industrial revolution due to mounting environmental threats that stem from the fourth and third industrial 
revolutions (Chen et al. 2018). (Chen 2008; Albort-Morant et al. 2016; Baloch et al. 2021; Coscieme et al. 2021; and Goyal et al. 2020) found that green innovation practices provide businesses with a way to gain a competitive edge while also providing multiple benefits such as green goodwill, stakeholder confidence, and a high share price, which is especially true if the firm is the first mover. Furthermore, Chen (2008) concluded by stating that a firm's effectiveness, efficiency, and profitability could be reached. This benefits a company both ecologically and financially. In the existing literature, various forms of green operational innovation-green product innovation (Tariq et al. 2017), green process innovation (Xie et al. 2019), and green service innovation (Khan and Johl 2019; Calabrese et al. 2018)are related to operational business activities.

\subsubsection{Green Product Innovation (GPI)}

GPI has bestowed numerous benefits amongst stakeholders during the innovation lifecycle. However, the development of green products is indolent in coinciding with future expectations, as stated by Ilg (2019). Green product innovation emboldens the economic and productive use of defined resources and depreciates waste to generate added earnings and fund flows (Khan et al. 2021d; Rehman et al. 2021).

Green product innovation also creates green goodwill, builds a unique market position, gains a competing advantage, and builds a green leadership reputation. Moreover, it turns into an immense benefit hotspot for organizations that are ready to create self-sufficient customers. Furthermore, Ar (2012) indicates that if businesses focus on innovating products and product environmental repercussions, these businesses will gain the upper hand over their rivals.

In Chen et al. (2006), the author found that GPI is wholly linked with an organization's competitive advantage. GPI depicts a firm's vision and mission and the "green mindfulness" of employees at every management level to stakeholders. Moreover, findings in Dangelico (2016) highlighted the benefit over the competitive advantage that improves market benefits, green reputation, and opportunities for innovation, leading to higher profits for the organization. The findings also showed that a high-quality management commitment influences the development of green product innovation.

Furthermore, the Qi et al. (2013) stated that stakeholders significantly influence foreign customers, which leads to pressure for businesses to adopt a green strategy in product innovation. In (Li et al. 2017; Weng et al. 2015), the authors stated that external legitimacy pressures such as ISO 14001 (Duque-Grisales et al. 2020; Ferrón-Vílchez 2016; Salim et al. 2018), competitors, and the government enhance eco-friendly product practices among service and manufacturing companies (Chen 2020).

In contrast, Qi et al. (2013) found evidence that community and institutional regulatory stakeholders have no significant effect on green product innovation. In Chang and Zhang (2019), the authors also supported this notion by researching green motives influencing green product innovation. They found no decisive nexuses amongst green co-production, green value in use, and green product innovation performance. Therefore, the following is hypothesized:

Hypothesis 3a (H3a). Green product innovation positively moderates the relationship between sustainable development goals (environmental and social SDGs) and firms' financial performance (ROA).

Hypothesis $\mathbf{3 b} \mathbf{( H 3 b ) . ~ G r e e n ~ p r o d u c t ~ i n n o v a t i o n ~ p o s i t i v e l y ~ m o d e r a t e s ~ t h e ~ r e l a t i o n s h i p ~ b e t w e e n ~ s u s - ~}$ tainable development goals (environmental and social SDGs) and firms' financial performance (ROE).

\subsubsection{Green Process Innovation (GPI)}

The debate on the growing phenomenon of process innovation across corporations signals the emergence of inductive thinking and creative design thinking, including new eco-friendly technology, green human resources, and green work practices to construct a structured approach to innovating green production processes. This can help organiza- 
tions maximize their operational capability and focus on customer value, mitigating the production and workplace risk.

Green process innovation is purposefully directed towards the production process. Although it is new to the focal firm, it can minimize environmental risk and other undesireable consequences. The literature recognizes methods such as clean production (Ma et al. 2017), pollution control (Xie et al. 2019), pollution prevention (Wong et al. 2020), eco-competence, and circular technology. Green process innovation is initiated by adopting clean technology and eco-saving equipment to enhance energy efficiency, maximize resource utilization, and eliminate greenhouse gas emissions (Dai and Zhang 2017).

GPI is the second critical component of green innovation. Tt focuses on mitigating harmful environmental impacts through waste control, water management, and sustainable raw material procurement (Khan and Johl 2020). Additionally, it improves organizational performance and reduces an organization's operating costs (Liu et al. 2020), allowing for revenue generation (Karabulut and Hatipoğlu 2020) and the development of trust among internal stakeholders (Khan and Johl 2020). This is because GPI eliminates a firm's incidents, thus providing a secure workplace for its workers. It also benefits companies in terms of revenue and draws external stakeholders' attention to their firm's performance.

Another study (Ma et al. 2018) researched green process innovation, the effect on the firm's image, and its benefits (Zehir and Ozgul 2020). The study found a positive relationship between long-term benefits and a non-significant relationship in the short term (Khan et al. 2021f). In Li et al. (2017), regarding legitimacy pressure, a positive influence on green innovation was found. Despite the various benefits of green process innovation, many researchers claim that many firms lag in adopting green process innovation. In Dai and Zhang 2017, the author found that this is due to a lack of complete customer awareness, the enforcement of green innovation by the government, and promoting sustainable investment.

In addition, the author of Visseren-Hamakers (2020) conducted initial research on sustainable and responsible investment markets focusing on life insurance and pension fund companies. The researched companies were found to maintain a regular investment follow-up to ensure sustainability. This research is the second that focused on sustainable and responsible investment to determine the relationship that sustainable, responsible investment has with eco-friendly operations and green process innovations. Therefore, the following hypothesis is proposed:

Hypothesis 4a (H4a). Green process innovation positively moderates the relationship between sustainable development goals (environmental and social SDGs) and firms' financial performance (ROA).

Hypothesis $4 \mathbf{b}(\mathbf{H} 4 \mathbf{b})$. Green process innovation positively moderates the relationship between sustainable development goals (environmental and social SDGs) and firms' financial performance (ROE).

\subsubsection{Green Organizational Innovation (GOI)}

Green organization innovation is a supportive innovation to operational innovation. This supporting innovation includes the procurement of raw materials, human resources, the development of infrastructure and technology, and collaboration. Green organizational innovation or supportive innovation supports innovation related to companies' products, processes, and services. Green organization innovation is gaining traction after various countries have made it mandatory to document environmental, social, and governance (ESG) data in their reporting.

These ESG data reflect a company's internal non-financial performance; these nonfinancial performances attract investors to these companies. In Visseren-Hamakers 2020, the author studied the disclosure of environmental and social information within the companies' report and found a significant and positive nexus between ESG and bankrelated profitability. 
This ESG disclosure of the companies reports the produced product, process, technology adoption, infrastructure, culture, and innovation, since disclosure can affect a firm's profitability. Likewise, an organization innovation-which this research defines as support innovation-can affect the innovation of products, processes, and services, which will lead to profitability and firm performance. This research examines the raw materials, supplier(s), infrastructure, technology used, organizational culture, and innovation strategy to measure green organizational innovation.

Further, various studies have been conducted on innovation strategy (Brogi and Lagasio 2019; Cassiman and Veugelers 2006; Pisano 2015) and found that the integration of innovation strategy with business strategy is the key to growth and success for an organization. Likewise, green innovation strategy research conducted by (Song and Yu 2018) resulted in a positive correlation between organizational identity and green creativity.

Green innovation strategy impacts an organization's innovation support activities such as adopting technology, building green infrastructure, procurement of green raw materials, development of green supply chain management, and emissions reduction. An organization's innovation support activities are created through its green organization identity and green creativity culture. Research conducted by Song and Yu (2018) on green innovation strategy - integrating green organization identity and green creativity-found that green innovation strategy has a positive relationship in creating a "green organization identity" and "green creative culture". Song and Yu (2018) also found a positive relationship between green organizational identity and green creative culture.

Therefore, to minimize emissions, waste, wastewater, energy consumption, organizational identity, and green creative culture plays a vital role in creating a support system or innovation to innovate an organization's products, processes, and services. On the other hand, the research conducted by Xiao and North (2018) found that the supporting activity can only help in innovation, leading to improvements in products, processes, and services, but that could not lead to revenue generation every time for the firm. This suggests the following research hypothesis:

Hypothesis 5a (H5a). Green organizational innovation positively moderates the relationship between sustainable development goals (environmental and social SDGs) and firms' financial performance (ROA).

Hypothesis $\mathbf{5 b} \mathbf{( H 5 b ) . ~ G r e e n ~ o r g a n i z a t i o n a l ~ i n n o v a t i o n ~ p o s i t i v e l y ~ m o d e r a t e s ~ t h e ~ r e l a t i o n s h i p ~}$ between sustainable development goals (environmental and social SDGs) and firms' financial performance (ROE).

\section{Methodology}

This section includes the essential components of the methodology of this study, such as sample selection criteria, content analysis, and instrument adoption for data collection.

\subsection{Sample and Data Collection}

This study is at the primary stage. Focusing on five regions, it has searched the top five countries (based on the GDP) and their blue-chip companies (Rodríguez and Chalmeta 2020) (based on the market capital). Therefore, the total sample size was 125; however, out of the sample of 125 units, 75 firm reports were not found in the English language. In total, data from 67 firms were collected for the final data analysis from each company's website between 2018 and 2019. The above sample selection is adopted directly from the literature, such as the data collection of blue-chip firms (Zeisel 2020) or top-listed firms (Aggarwal and Singh 2019) across two consecutive years (Kraak et al. 2018). A total sample of 67 firms and two-year observations in this preliminary study yielded 134 observations, as shown in Table 2 . Table 2 shows the number of companies adopted as per the continent 
and multiplied by two years, which totals 134 observations. The following section discusses the data collection process.

Table 2. Number of observations.

\begin{tabular}{cccc}
\hline Continent. & Country N & Company N & Number of Observations \\
\hline Europe & 4 & 19 & 38 \\
Australia and New Zealand & 2 & 10 & 20 \\
Asia & 4 & 15 & 30 \\
North America & 3 & 11 & 22 \\
Africa & 3 & 12 & 24 \\
\hline Total & & & 134 \\
\hline
\end{tabular}

\subsection{Content Analysis Procedure}

Content analysis is widely accepted in the assessment of business reporting in the literature regarding sustainability (Amini et al. 2018) and sustainable development goals (Erin and Bamigboye 2021; Gerged and Almontaser 2021; Yadav et al. 2021). The authors downloaded company annual reports, sustainability reports, and sometimes collected website data for initiating content analysis (Zhang et al. 2020a). The content analysis searches the relevant corporate information and codes it (numerically). This research uses "code $=0$ " if the firm is not practiced, whereas "code $=1$ " is regarded as practicing (Xie et al. 2019). After the report collection, this research assumed that companies report their sustainable development goals (environmental and social SDG) and green innovation (products, processes, and services) in their sustainable reports and annual reports. Therefore, a company's report content analysis is used to determine whether an organization is measured through sustainable development goals and green innovation. The adopted measurement variable is available in Appendix A (Table A1).

\subsection{Instrument Adoption}

Instrument development and validation involve three phases: (1) construction of the conceptual framework and item generation; (2) judgment quantification; (3) psychometric testing of instrument properties (instrument reliability and validity) - as suggested by (Kääriäinen et al. 2020). The item of measurement was generated after an extensive literature analysis. The independent variable, the firm's sustainable development goals, was adopted from the literature (Khan et al. 2021d) to measure the firms' practice of the United Nations' 17 SGDs, whereas the moderating variable "green innovation", ranked as per the repetition of the item in the exiting instrument and the highest recurring item, was adopted for green products, processes, and organizational innovation. On the other hand, the dependent variable "financial performance" was measured through financial ratios, namely, return on asset (ROA) and return on equity (ROE) (Xu et al. 2021; Yi et al. 2021), to evaluate the firms' performance.

The second phase of instrument development was the judgment quantification by experts, academics, industry professionals, and policymakers. For this, the author incorporated two industry experts, an academic, and one policymaker; and their suggestions were incorporated and improved to capture the firm's green innovation and reporting.

In the third phase, the psychometric testing of the instruments' properties (instrument reliability and validity), the sustainable development goal reliability test (Cronbach's alpha 0.73 ), and green innovation (Cronbach's alpha 0.755-which provides good reliability statistics above 0.7 ) were carried out and shown in Table 3. A similar approach is also adopted in the research (Chen 2016). 
Table 3. Reliability and validity tests.

\begin{tabular}{|c|c|c|c|}
\hline Variable & Measurement Criteria & Cronbach's Alpha & Reference \\
\hline \multicolumn{4}{|c|}{ Independent Variable } \\
\hline Sustainable development goal & $\begin{array}{l}\text { Environmental SDGs } \\
\text { Social SDGs }\end{array}$ & 0.73 & (Khan et al. 2021d) \\
\hline \multicolumn{4}{|c|}{ Moderating Variables } \\
\hline \multirow{3}{*}{ Green innovation } & Green process innovation (GPRI) & \multirow{3}{*}{0.755} & (Palčič and Prester 2020) \\
\hline & Green product innovation (GPI) & & (Das et al. 2000) \\
\hline & Green organization innovation (GOI) & & GRI \\
\hline \multicolumn{4}{|c|}{ Dependent Variables } \\
\hline Firms' financial performance & $\begin{array}{l}\text { Return on asset } \\
\text { Return on equity }\end{array}$ & 0.7 & $\begin{array}{c}\text { (Jan et al. 2018; Xu et al. 2021; } \\
\text { Yi et al. 2021) }\end{array}$ \\
\hline
\end{tabular}

After collecting and entering the data, this research explored, examined, and addressed outliers using the explore command in SPSS to identify outliers and influential observations in the dataset. In total, 18 observations were eliminated from the final observation for data analysis.

\subsection{Model Development}

This study employed panel data estimation since panel regression is different from general time series and cross-sectional regression models (Akhtar et al. 2021). It incorporates double subscript and helps control individual heterogeneity by allowing firm-specific random or fixed-effect components (Baltagi 2008).

Secondly, the panel data approach provides greater variation in datasets, high information data, less multicollinearity with high efficiency, and degrees of freedom (Gujarati and Porter 2009). The model used in this research consists of $n$ cross-sectional units, $n=1, \ldots, N$ observed at each $t$ time period, $t=1, \ldots, T$. The total observation in the dataset is $n \times t$ (Akhtar et al. 2020; Brooks 2019). The following panel regression model uses the same panel dataset structure as designed:

$$
y_{n t}=\alpha+\beta x_{n t}+e_{n t}
$$

where $y_{n t}$ refers to the regress, $\alpha$ refers to the intercept term, $\beta$ is the $K \times 1$ vector of the parameter to be estimated, and $x_{n t}$ is the $n$th observations on $K$ regressors, which is $1 \times k$, $t=1, \ldots, T, n=1, \ldots, N$. The operational form of the model is:

$$
\text { Financial performance }=\mathrm{f} \text { (S.D.G.s, green innovations) }
$$

where ROA and ROE measure financial performance as dependent variables, the SDGs' 17 goals, formulated by the United Nations (Environmental and Social), are treated as the independent variable, green product, and green process, and green organization innovations are green innovations parameters that are used as moderators. In addition, the current study has employed the fixed and random effects model for estimating panel data equations. Further, Hausman's test is employed to decide between random or fixed effects; the null hypothesis corresponds to the random effects and is an appropriate model.

\section{Preliminary Results and Discussion}

Table 4 presents the descriptive statistics of the major variable adopted in the research, ROE and ROA as dependent variables, 17 SDGs (environmental and social) as the independent variable, and green innovation, namely, green product innovation, green process innovation, and green organizational innovation as moderating variables. 
Table 4. Descriptive statistics.

\begin{tabular}{lccc}
\hline \multicolumn{1}{r}{ Variable } & Obs. & Mean & Std. Dev. \\
\hline ROA & 134 & 5.510 & 4.240 \\
ROE & 134 & 16.146 & 8.748 \\
ENVTSDG & 134 & 0.330 & 0.348 \\
SCOSDG & 134 & 0.322 & 0.326 \\
GPI & 134 & 0.320 & 0.235 \\
GPRI & 134 & 0.576 & 0.220 \\
GOI & 134 & 0.416 & 0.218 \\
\hline
\end{tabular}

Table 5 presents the Pearson correlation coefficients of the variables. The results highlight that all the SDGs are significantly correlated with the financial performance parameters, whereas in the green innovations only the green process innovation is significantly associated with the financial performance, while the remaining sub-variable, green innovation, is insignificantly correlated.

Table 5. Pearson correlation matrix.

\begin{tabular}{lcccccc}
\hline \multicolumn{1}{c}{ VARIABLES } & $\mathbf{( 1 )}$ & $\mathbf{( 2 )}$ & $\mathbf{( 3 )}$ & $\mathbf{( 4 )}$ & $\mathbf{( 5 )}$ & $\mathbf{( 6 )}$ \\
\hline (1) ROA & 1.000 & & & & & \\
(2) ROE & $0.693^{* * *}$ & 1.000 & & & & \\
(3) ENVTSDG & $-0.020^{*}$ & $-0.145^{* *}$ & 1.000 & & & \\
(4) SOCSDG & $-0.061^{* *}$ & $-0.171^{* *}$ & $0.792^{* * *}$ & 1.000 & & \\
(5) GPI & $0.094^{* * *}$ & -0.022 & $0.250^{* * *}$ & $0.226^{* * *}$ & 1.000 & 1.000 \\
(6) GPRI & $-0.071^{* * *}$ & $-0.181^{* *}$ & $0.299^{* * *}$ & $0.292^{* * *}$ & $0.677^{* * *}$ & $0.491^{* * *}$ \\
(7) GOI & $0.108^{* * * * *}$ & -0.025 & 0.069 & 0.033 & $0.624^{* * *}$ & 1.000 \\
\hline
\end{tabular}

$* * *, * *$, and ${ }^{*}$ denote level of significance at $1 \%, 5 \%$, and $10 \%$. Source: Author's calculation (STATA).

In static panel regression, the major issue is the presence of multicollinearity. As our small dataset comprises 67 cross-sections with two years, it is essential to test multicollinearity before conducting the regression. It was found that the data are free from multicollinearity, since the results showing the relationship between the independent and moderating variables are under the benchmark, i.e., 0.80 (Gujarati and Porter 2009) which is reflected in Table 4.

The next diagnostic test is the heteroscedasticity test, which assesses the variances in error terms. The Breusch-Pagan test is conducted for heteroscedasticity (Adepoju and Ojo 2018; Khan et al. 2021c). If any model is found to have heteroscedasticity, then, in that case, the robust Huber-White sandwich estimator will be employed in the regression analysis to overcome the heteroscedasticity issue. In addition, the Hausman test is conducted to identify the best estimator between fixed effects and random effects. The Hausman results show a selection of random effect regression in all models, since the value was over 0.05 (null: random; alt: fixed). Hence, the random effect was identified as the best estimator to run the regression.

\subsection{Regression Results}

Table 6 illustrates the regression result of the practice of 17 SDGs on the financial performance, along with the moderation of the green innovation variable, namely, green product innovation (GPI), green process innovation (GPRI), and green organizational innovation (GOI). It depicts the four crucial models of this study, explaining the mixed result of the positive and negative correlations. 
Table 6. Regression results.

\begin{tabular}{|c|c|c|c|c|}
\hline & \multicolumn{2}{|c|}{ Return on Assets (ROA) } & \multicolumn{2}{|c|}{ Return on Equity (ROE) } \\
\hline & Model 1 & Model 2 & Model 3 & Model 4 \\
\hline \multicolumn{5}{|c|}{ Predictors } \\
\hline ENVTSDG & $\begin{array}{c}8.905 * * \\
(1.99)\end{array}$ & $\begin{array}{l}5.094 \text { * } \\
(1.89)\end{array}$ & $\begin{array}{c}10.031 \text { * } \\
(1.09)\end{array}$ & $\begin{array}{c}4.545^{*} \\
(0.81)\end{array}$ \\
\hline SOCSDG & $\begin{array}{c}-10.041 * * \\
(-2.10)\end{array}$ & $\begin{array}{l}-6.259 * \\
(-1.87)\end{array}$ & $\begin{array}{l}-15.005^{* *} \\
(-1.52)\end{array}$ & $\begin{array}{c}-10.256^{*} \\
(-1.49)\end{array}$ \\
\hline \multicolumn{5}{|c|}{ Moderators } \\
\hline GPI & & $\begin{array}{l}1.415^{*} \\
(0.38)\end{array}$ & & $\begin{array}{l}6.134 \\
(0.79)\end{array}$ \\
\hline GPRI & & $\begin{array}{c}-5.975^{* *} \\
(-1.84)\end{array}$ & & $\begin{array}{c}-14.883^{* *} \\
(-2.20)\end{array}$ \\
\hline GOI & & $\begin{array}{c}5.852 * * \\
(1.86)\end{array}$ & & $\begin{array}{l}6.448^{*} \\
(0.98)\end{array}$ \\
\hline SDG ${ }^{*}$ GPI & & $\begin{array}{l}6.409 * \\
(0.75)\end{array}$ & & $\begin{array}{l}-1.963^{* *} \\
(-0.11)\end{array}$ \\
\hline SDG*GPRI & & $\begin{array}{l}9.331 \text { * } \\
(1.06)\end{array}$ & & $\begin{array}{c}18.598 \text { * } \\
(1.01)\end{array}$ \\
\hline SDG*GOI & & $\begin{array}{c}-15.778^{* *} \\
(-2.16)\end{array}$ & & $\begin{array}{c}-16.646^{*} \\
(-1.09)\end{array}$ \\
\hline Constant & $\begin{array}{c}5.805^{* * *} \\
(11.35)\end{array}$ & $\begin{array}{c}6.178^{* * *} \\
(3.77)\end{array}$ & $\begin{array}{c}17.670 * * * \\
(16.79)\end{array}$ & $\begin{array}{c}21.141^{* * * *} \\
\quad(6.19)\end{array}$ \\
\hline R-squared & 0.146 & 0.197 & 0.124 & 0.157 \\
\hline F-test & $2.23 * *$ & $2.69 * *$ & $2.60 *$ & $1.58^{* *}$ \\
\hline $\begin{array}{c}\text { No. of } \\
\text { observations }\end{array}$ & 134 & 134 & 134 & 134 \\
\hline
\end{tabular}

Models 1 and 3 explain the impact of SDGs on firms' financial performance (ROA and ROE), whereas the other two models ( 2 and 4 ) explain the moderating role of green innovation on the relationship between SDGs and firms' financial performance (ROA and ROE). Model 1 resulted in a positive impact of environmental SDGs (ENVTSDG) on ROA due to the investment and initiative to improve the firms' resources, minimize production costs, and maximize the output. Similarly, the analysis also shows a positive relationship with the return on equity.

The adoption of environmental SDG practice has a significant impact on a company's financial performance, as environmental practices-as a core business strategy-allow enterprises to minimize production costs by lowering environmental hazards, according to the natural resource-based view and stakeholder theory, which also helps to gain a competitive advantage and, as a result, benefits the long-term financial health of businesses (Danso et al. 2019; Manrique and Martí-Ballester 2017). In line with the above discussion, the literature shows that firms in developing countries require a more significant adoption of environmental practices, and developed countries could move to advanced levels of environmental practices (Manrique and Martí-Ballester 2017).

In addition, Table 5 shows a significant negative impact of social SDGs (SOCSDG) on ROA and ROE at the 5\% level of significance. This is due to capital investment and initiatives on social SDGs. The investment on social SDGs and related initiatives are not linked to a firm's operational activities, due to the noticeable return being reflected in the long term. The firm engaged in social SDG activities to return to society and address stakeholder demands (Calabrese et al. 2021). There is limited literature on social SDGs and their effect on the financial performance of firms. However, there is similar literature on social responsibility, which has reported a high return if a firm can demonstrate the full integration of social SDGs into its operational activities, along with recorded evidence that 
the firm was involved in fulfilling its social responsibility, showing an increase in sales, with a premium price and a reduced employee turnover rate.

\section{Moderation Effect of Green Innovation}

Model 2 explains the moderation of green innovation over the relationship of SDGs over ROA, resulting in a significantly impacted ROA (SDG ${ }^{*}$ GPI and SDG*GPRI positively impacted ROA), due to EVNTSDG and GPI being significantly positive, and green innovation (green products and green processes) activities are eco-friendly and improve the environmental SDGs. However, the SDG ${ }^{*}$ GOI has a negative impact on ROA. In the short term, i.e., two years, these green innovation practices and investments generate eco-friendly products and processes that appeal to sustainable consumers and create a green culture or a strategy of performing operational and non-operational activities.

However, the literature on green business practices provides evidence of improvement and attracting sustainable investment to enhance business operations and save resources for operational and non-operational activities in the long term (Song and Yu 2018; Weng et al. 2015). In the long term, green innovation techniques enable businesses to simultaneously meet legislative and industry regulations, reduce waste and pollution, protect the environment, boost competitiveness, and generate revenue (Huang and Li 2018; Khan et al. 2021c). Thus, H3a H4a are supported, and H5a is not supported.

Lastly, model 4 also explains the moderating role of green innovation between SDGs and ROE. The direct relationship between sustainable development goals and the return on equity is shown to be significant. In Table 5, the moderation of green process innovation and green organizational innovation was also shown to be significant; however, green product innovation was insignificant. The interaction model parameters significantly impacted the return on equity (SDG* GPRI positively impacts ROE), thus supporting H4b. On the contrary, GPI negatively moderates ROE because the investment in green products generates products that appeal to sustainable consumers in the short term; however, the revenue generation is expected to be reflected in the long term (Khan et al. 2021c).

Similarly, the moderation of green organizational innovation (GOI) was shown to have a significantly negative impact on the relationship between SDG and ROE, as the green organization innovation requires capital investment such as green building, green building certification (Samad et al. 2020), and green culture (García-Machado and MartínezÁvila 2019), which involves a long period of development and revenue generation. Green organization innovation is also considered as green support activities that boost a firm's operational activities, leading to a boost in output and book value for a short period. However, reflecting on equity requires consistency, continuous improvement, and communication with stakeholders (Oskooei 2021), since continuous communication generates awareness of green initiatives and investments that are created to mitigate environmental challenges. Therefore, the results do not support $\mathrm{H} 3 \mathrm{~b}$ and $\mathrm{H} 5 \mathrm{~b}$ from the two-year study; however, it seems optimistic in the long term.

\section{Implication}

The influx of environmental and social challenges has raised concerns from researchers and policymakers. Moreover, the world has also experienced a fall in greenhouse gas emissions, waste generation, and other environmental challenges due to the COVID-19 pandemic. However, these environmental concerns are expected to rise two-fold as the pandemic regresses to an endemic phase. Therefore, this study recommends that firms unlearn the individualist reactive approach and learn a proactive collective approach to successfully implement sustainable development goals. This can be seen as a new way forward to address these challenges, and all SGDs should act accordingly, within an interconnected network. 
Moreover, this research expressed the imperativeness of a proactive and collective approach of practicing the United Nations' 17 SDGs at the firm level without compromising the organization's financial performance and green innovation activities. Green innovation practices minimize the cost of production, save resources, and can address and contribute to environmental SDGs. The study has several practical and policymaker-related implications, as highlighted below.

\subsection{Practical Implications}

This research contributes significantly to all industries. In particular, it contributes widely to heavily polluting industries such as the chemical, oil and gas, agriculture, and textiles industries, which are responsible for large-scale pollution. Firms can map their activities to the aforementioned SDGs to create a collective and collaborative approach to meet the 17 UN SDGs. For instance, greener solvents such as ionic liquids are being used in the pharmaceutical industry (Khan et al. 2021a), green emulsion liquid membranes are being used for the removal of biologically active drug molecules from wastewater (Khan et al. 2021b; Ting et al. 2021), and the production of biodiesel from waste vegetable oil is being undertaken to mitigate waste emissions (Khan and Athar 2015) and oil spill (Khan et al. 2020). All of these initiatives can be mapped to the SDGs: SDG 9, SDG 12, SDG 13, and SDG 14.

In addition, while collecting data, we noticed a significant improvement in practices from 2018 to 2019: the highest contributions witnessed in European countries; secondhighest in Asia; the third-highest in Africa; and the lowest in Australia and New Zealand (Appendix A-Table A2). This shows that the implementation lacks a collective approach across all continents, which shows the urgent need to incorporate all 17 SDGs, especially in the chemical, oil and gas, agriculture, and textile industries, responsible for large-scale environmental and social challenges.

Practices by larger firms will encourage other firms to incorporate or map firm practices. According to the findings related to the direct relationship of the UN 17 SDGs, the minimal practices have a positive impact on firms' financial performance. Therefore, this research advocates maximizing the SDG practices in the operational and non-operational business activities of individual firms. This will create a collective approach that will assist the United Nations' aim to achieve its 17 SDGs and 169 targets by 2030.

On the other hand, this research also investigated the moderating effect of green innovation. The findings have mixed results. For instance, the green innovation practices show negative signs of product and organizational innovation activities. However, a positive significance of green process innovation is found in the short term. These negative significances of green product innovation and green organizational innovation are due to the two-year study period, since green innovation requires capital investments that impact profits over the short term. However, this investment maximizes a firm's production process with limited resources.

Moreover, these investments also create products that are more appealing to stakeholders, which maximizes revenue generation in the following financial year. Moreover, investment in recent technologies or upgrading production processes can help firms avoid mishaps and fines. Therefore, this study strongly advocates that businesses invest in "greening" their business practices, which will contribute directly to environmental SDGs and indirectly to social SDGs without impacting a firm's financial performance. 


\subsection{Policy-Making Implications}

Environmental issues and data transparency, such as greenhouse gas emissions, waste control, water management, and other topics, are being debated by the United Nations in order to reduce environmental pollution and its societal effects. Due to various ecological challenges, different strategies have been developed and adopted, such as integrating reporting - which the firms (across various countries) are obliged to publish-and various reporting standards (global reporting standards) have been formed from disclosing business practices to stakeholders.

This research draws the attention of policymakers and global reporting initiatives to promote SDG practices for minimizing the environmental challenges at the innovative stage, mitigating existing environmental challenges, enriching sustainability disclosure for stakeholders.

Secondly, policymakers can understand the imperative of the United Nations' 17 SDGs in this research with the positive moderation of green process innovation on a firm's sustainable development goals and financial performance. This mainly includes: climate action (SDG 13), responsible consumption and production (SDG 12), industry, innovation, and infrastructure (SDG 9), and decent work and economic growth (SDG 8), which is also stated by Zhou (Zhou et al. 2020). In addition, operational business activities-which indirectly contribute to other SDGs -include good health and wellbeing (SDG 3), clean water and sanitation (SDG 6), affordable clean energy (SDG 7), sustainable cities and communities (SDG 11), life below water (SDG 14), life on land (SDG 15), and promoting peaceful and inclusive societies (SDG 16).

Lastly, there is an ongoing debate regarding the 18th SDG, on animal health, welfare, and rights, which the United Nations has neglected. This will require further attention from policymakers, who are encouraged to provide their input for animal health, welfare, and rights.

\section{Limitation and Future Research}

This study has a few limitations. Firstly, the small number of observations $(n=137)$ creates a hurdle for generalizing the results. Secondly, this study did not cover green behavior (employees) and green suppliers in green innovation. Thirdly, the study adopted two accounting ratios to measure firms' financial performance. Future research should adopt Tobin's Q to address market perspectives and non-financial permanence parameters to measure business operational performance. Lastly, additional regression analyses (GMM, 2LS, and 3LS) should be adopted in future research in order to generalize the results. However, the current findings can be applied to all blue-chip firms around the world.

Author Contributions: Conceptualization, P.A.K.; data curation, P.A.K.; formal analysis, P.A.K. and S.A.; investigation, P.A.K. and S.A.; methodology, P.A.K. and S.A.; supervision, S.K.J.; validation, P.A.K.; writing-original draft, P.A.K. and S.A.; writing-review and editing, P.A.K., S.K.J. and S.A. All authors have read and agreed to the published version of the manuscript.

Funding: This study is funded by the two grant YUTP-015LCO-368 and matching fund of UTP Malaysia and Uhamka Indonesia 015ME0-174.

Data Availability Statement: Available on Request.

Acknowledgments: The authors would like to thank the MH Department of Universiti Teknologi PETRONAS, Malaysia, for facilitating the support in conducting this research.

Conflicts of Interest: The authors declare no conflict of interest. 


\section{Appendix A}

Table A1. Detailed Criteria in Selection Variable Measurement.

\begin{tabular}{|c|c|c|c|}
\hline Variable & Measurement Criteria & Data Source & Reference \\
\hline \multicolumn{4}{|c|}{ Independent Variable } \\
\hline $\begin{array}{l}\text { Sustainable development } \\
\text { goal }\end{array}$ & $\begin{array}{c}\text { Environmental SDGs } \\
\text { SDG } 6 \text { Clean water and sanitation } \\
\text { SDG } 7 \text { Renewable energy } \\
\text { SDG } 9 \text { Innovation and infrastructure } \\
\text { SDG } 10 \text { Reduce inequalities } \\
\text { SDG } 11 \text { Sustainable cities and communities } \\
\text { SDG } 12 \text { Responsible consumption } \\
\text { SDG } 13 \text { Climate action } \\
\text { SDG } 14 \text { Life below water } \\
\text { SDG } 15 \text { Life on land } \\
\text { SDG } 17 \text { Partnership for the goals } \\
\text { Social SDGs } \\
\text { SDG } 1 \text { No poverty } \\
\text { SDG } 2 \text { Zero hunger } \\
\text { SDG } 3 \text { Good health } \\
\text { SDG } 4 \text { Quality education } \\
\text { SDG } 5 \text { Gender equality } \\
\text { SDG 8 Good jobs and economic growth } \\
\text { SDG } 16 \text { Peace and justice } \\
\text { SDG } 17 \text { Partnership for the goals }\end{array}$ & $\begin{array}{l}\text { Sustainability } \\
\text { reports }\end{array}$ & (Khan et al. 2021d) \\
\hline
\end{tabular}

\section{Moderating Variables}

Green Innovation

Product innovation-Green

Green product innovation goal

ISO 14001 certification

Green product innovation (GPI)
Disassembly and disposal Eco-labeling

Lifecycle effect on environment

Continues improvement/innovation Green packaging

Emission intensity (per product) improvement

Green process innovation

(GPRI)
Emission of waste, efficiency of energy, green materials, green technology, emission minimization, and green business certification Inc. (GBCI)

\begin{tabular}{|c|c|c|c|}
\hline $\begin{array}{l}\text { Green organization } \\
\text { innovation }(\mathrm{GOI})\end{array}$ & $\begin{array}{l}\text { Green building certification, green business } \\
\text { certification Inc. (GBCI), and SITES certification }\end{array}$ & $\begin{array}{l}\text { Sustainability } \\
\text { reports }\end{array}$ & GRI \\
\hline \multicolumn{4}{|c|}{ Dependent Variables } \\
\hline $\begin{array}{l}\text { Firms' financial } \\
\text { performance }\end{array}$ & $\begin{array}{l}\text { Return on assets (ROA), and return on equity } \\
\text { (ROE) }\end{array}$ & $\begin{array}{l}\text { Annual report and } \\
\text { third-party website } \\
\text { (Investing.com) }\end{array}$ & $\begin{array}{l}\text { (Xu et al. 2021; } \\
\text { Yi et al. 2021) }\end{array}$ \\
\hline
\end{tabular}


Table A2. Practice of Environmental and Social SDGs.

\begin{tabular}{|c|c|c|c|c|c|c|c|c|c|c|c|c|c|c|c|c|c|}
\hline \multirow[b]{2}{*}{ Continents } & \multicolumn{9}{|c|}{ Environmental SDGs } & \multicolumn{8}{|c|}{ Social SDGs } \\
\hline & G6 & G7 & G9 & G10 & G12 & G13 & G14 & G15 & G17 & G1 & G2 & G3 & G4 & G5 & G8 & G16 & G17 \\
\hline Europe & $28 \%$ & $43 \%$ & $33 \%$ & $33 \%$ & $32 \%$ & $40 \%$ & $18 \%$ & $33 \%$ & $37 \%$ & $33 \%$ & $37 \%$ & $28 \%$ & $43 \%$ & $32 \%$ & $40 \%$ & $18 \%$ & $37 \%$ \\
\hline Asia & $39 \%$ & $25 \%$ & $24 \%$ & $20 \%$ & $25 \%$ & $21 \%$ & $27 \%$ & $20 \%$ & $16 \%$ & $24 \%$ & $16 \%$ & $39 \%$ & $25 \%$ & $25 \%$ & $21 \%$ & $27 \%$ & $16 \%$ \\
\hline Africa & $11 \%$ & $11 \%$ & $14 \%$ & $13 \%$ & $11 \%$ & $12 \%$ & $9 \%$ & $13 \%$ & $21 \%$ & $14 \%$ & $21 \%$ & $11 \%$ & $11 \%$ & $11 \%$ & $12 \%$ & $9 \%$ & $21 \%$ \\
\hline North America & $11 \%$ & $7 \%$ & $9 \%$ & $27 \%$ & $14 \%$ & $12 \%$ & $37 \%$ & $27 \%$ & $10 \%$ & $9 \%$ & $10 \%$ & $11 \%$ & $7 \%$ & $14 \%$ & $12 \%$ & $37 \%$ & $10 \%$ \\
\hline Australia & $5 \%$ & $7 \%$ & $10 \%$ & $7 \%$ & $7 \%$ & $6 \%$ & $9 \%$ & $7 \%$ & $11 \%$ & $10 \%$ & $11 \%$ & $5 \%$ & $7 \%$ & $7 \%$ & $6 \%$ & $9 \%$ & $11 \%$ \\
\hline New Zealand & $6 \%$ & $7 \%$ & $10 \%$ & $0 \%$ & $11 \%$ & $9 \%$ & $0 \%$ & $0 \%$ & $5 \%$ & $10 \%$ & $5 \%$ & $6 \%$ & $7 \%$ & $11 \%$ & $9 \%$ & $0 \%$ & $5 \%$ \\
\hline
\end{tabular}

\section{References}

Aastvedt, Tonje Marthinsen, Niaz Bashiri Behmiri, and Li Lu. 2021. Does green innovation damage financial performance of oil and gas companies? Resources Policy 73: 102235. [CrossRef]

Adepoju, Adedayo A., and Oluwadare O. Ojo. 2018. Bayesian method for solving the problem of multicollinearity in regression. Afrika Statistika 13: 1823-34.

Aggarwal, Priyanka, and Ajay Kumar Singh. 2019. CSR and sustainability reporting practices in India: An in-depth content analysis of top-listed companies. Social Responsibility Journal 15: 1033-53. [CrossRef]

Ahmad, Jamilah, Fauziah Md. Taib, and Amin Jan. 2021. Exploring CSR Initiatives to Cultivate and Nurture Values in Facing Issues Related to Drugs Abuse among the Youth in Malaysia: Using Three Core Components of Triple Bottom Line (TBL). Business Management and Strategy 12: 133-44. [CrossRef]

Akhtar, Shakeb, Tasneem Khan, and Parvez Alam Khan. 2020. Examine the key drivers affecting bottom line: A panel estimation study of Indian commercial bank. Journal of Critical Reviews 7: 2020.

Akhtar, Shakeb, Mahfooz Alam, and Mohd Shamim Ansari. 2021. Measuring the performance of the Indian banking industry: Data envelopment window analysis approach. Benchmarking: An International Journal. [CrossRef]

Albort-Morant, Gema, Antonio Leal-Millán, and Gabriel Cepeda-Carrión. 2016. The antecedents of green innovation performance: A model of learning and capabilities. Journal of Business Research 69: 4912-17. [CrossRef]

Amini, Mehdi, Carol C. Bienstock, and John A. Narcum. 2018. Status of corporate sustainability: A content analysis of Fortune 500 companies. Business Strategy and the Environment 27: 1450-61. [CrossRef]

Ar, Ilker Murat. 2012. The impact of green product innovation on firm performance and competitive capability: The moderating role of managerial environmental concern. Procedia-Social and Behavioral Sciences 62: 854-64. [CrossRef]

Asni, Nur, and Dian Agustia. 2021. The mediating role of financial performance in the relationship between green innovation and firm value: Evidence from ASEAN countries. European Journal of Innovation Management. [CrossRef]

Baloch, Muhammad Awais, Ilhan Ozturk, Festus Victor Bekun, and Danish Khan. 2021. Modeling the dynamic linkage between financial development, energy innovation, and environmental quality: Does globalization matter? Business Strategy and the Environment 30: 176-84. [CrossRef]

Baltagi, Badi H. 2008. Forecasting with panel data. Journal of Forecasting 27: 153-73. [CrossRef]

Brogi, Marina, and Valentina Lagasio. 2019. Environmental, social, and governance and company profitability: Are financial intermediaries different? Corporate Social Responsibility and Environmental Management 26: 576-87. [CrossRef]

Brooks, Chris. 2019. Introductory Econometrics for Finance. Cambridge: Cambridge University Press.

Cai, Wei, Conghu Liu, Cuixia Zhang, Minda Ma, Weizhen Rao, Wenyi Li, Kang He, and Mengdi Gao. 2018. Developing the ecological compensation criterion of industrial solid waste based on emergy for sustainable development. Energy 157: 940-48. [CrossRef]

Calabrese, Armando, Carolina Castaldi, Giampiero Forte, and Nathan Ghiron Levialdi. 2018. Sustainability-oriented service innovation: An emerging research field. Journal of Cleaner Production 193: 533-48. [CrossRef]

Calabrese, Armando, Roberta Costa, Massimo Gastaldi, Nathan Levialdi Ghiron, and Roberth Andres Villazon Montalvan. 2021. Implications for Sustainable Development Goals: A framework to assess company disclosure in sustainability reporting. Journal of Cleaner Production 319: 128624. [CrossRef]

Calza, Francesco, Adele Parmentola, and Ilaria Tutore. 2017. Types of Green Innovations: Ways of Implementation in a Non-Green Industry. Sustainability 9: 1301. [CrossRef]

Cassiman, Bruno, and Reinhilde Veugelers. 2006. In search of complementarity in innovation strategy: Internal R\&D and external knowledge acquisition. Management Science 52: 68-82.

Chang, Yu, and Tao Zhang. 2019. The Effects of Product Consistency and Consumer Resistance to Innovation on Green Product Diffusion in China. Sustainability 11: 2702. [CrossRef]

Chaturvedi, Khushboo, Shakeb Akhtar, Naghma Azhar, and Mohd Shamshad. 2021. Impact of Corporate Social Responsibility on Financial Performance of Selected Banks in India: Based on Camel Model. Studies in Economics and Business Relations 2: 17-31. 
Chen, Yu-Shan. 2008. The driver of green innovation and green image-green core competence. Journal of Business Ethics 81: 531-43. [CrossRef]

Chen, Si-Hua. 2016. The influencing factors of enterprise sustainable innovation: An empirical study. Sustainability 8: 425. [CrossRef]

Chen, Chun-Liang. 2020. Cross-disciplinary innovations by Taiwanese manufacturing SMEs in the context of Industry 4.0. Journal of Manufacturing Technology Management 31: 1145-68. [CrossRef]

Chen, Yu-Shan, Shyh-Bao Lai, and Chao-Tung Wen. 2006. The influence of green innovation performance on corporate advantage in Taiwan. Journal of Business Ethics 67: 331-39. [CrossRef]

Chen, Jin, Ximing Yin, and Liang Mei. 2018. Holistic innovation: An emerging innovation paradigm. International Journal of Innovation Studies 2: 1-13. [CrossRef]

Coscieme, Luca, Lars F. Mortensen, and Ian Donohue. 2021. Enhance environmental policy coherence to meet the Sustainable Development Goals. Journal of Cleaner Production 296: 126502. [CrossRef]

Costanza, Robert, Lew Daly, Lorenzo Fioramonti, Enrico Giovannini, Ida Kubiszewski, Lars Fogh Mortensen, Kate E. Pickett, Kristin Vala Ragnarsdottir, Roberto De Vogli, and Richard Wilkinson. 2016. Modelling and measuring sustainable wellbeing in connection with the UN Sustainable Development Goals. Ecological Economics 130: 350-55. [CrossRef]

Dai, Rui, and Jianxiong Zhang. 2017. Green process innovation and differentiated pricing strategies with environmental concerns of South-North markets. Transportation Research Part E-Logistics and Transportation Review 98: 132-50. [CrossRef]

Dalampira, Evropi-Sofia, and Stefanos A. Nastis. 2020. Mapping sustainable development goals: A network analysis framework. Sustainable Development 28: 46-55. [CrossRef]

Dangelico, Rosa Maria. 2016. Green Product Innovation: Where we are and Where we are Going. Business Strategy and the Environment 25: 560-76. [CrossRef]

Danso, Albert, Samuel Adomako, Joseph Amankwah-Amoah, Samuel Owusu-Agyei, and Renata Konadu. 2019. Environmental sustainability orientation, competitive strategy and financial performance. Business Strategy and the Environment 28: 885-95. [CrossRef]

Das, Sanchoy K., Pradeep Yedlarajiah, and Raj Narendra. 2000. An approach for estimating the end-of-life product disassembly effort and cost. International Journal of Production Research 38: 657-73. [CrossRef]

Duque-Grisales, Eduardo, Javier Aguilera-Caracuel, Jaime Guerrero-Villegas, and Encarnación García-Sánchez. 2020. Does green innovation affect the financial performance of Multilatinas? The moderating role of ISO 14001 and R\&D investment. Business Strategy and the Environment 29: 3286-302.

Erin, Olayinka Adedayo, and Omololu Adex Bamigboye. 2021. Evaluation and analysis of SDG reporting: Evidence from Africa. Journal of Accounting E Organizational Change. [CrossRef]

Fatemi, Ali, Martin Glaum, and Stefanie Kaiser. 2018. ESG performance and firm value: The moderating role of disclosure. Global Finance Journal 38: 45-64. [CrossRef]

Ferrón-Vílchez, Vera. 2016. Does symbolism benefit environmental and business performance in the adoption of ISO 14001? Journal of Environmental Management 183: 882-94. [CrossRef] [PubMed]

García-Machado, Juan J., and Minerva Martínez-Ávila. 2019. Environmental performance and green culture: The mediating effect of green innovation. An application to the automotive industry. Sustainability 11: 4874. [CrossRef]

Gerged, Ali Meftah, and Tariq Almontaser. 2021. Corporate adoption of SDG reporting in a non-enabling institutional environment: Insights from Libyan oil industries. Resources Policy 74: 102240. [CrossRef]

González-Ruiz, Juan David, Sergio Botero-Botero, and Eduardo Duque-Grisales. 2018. Financial eco-innovation as a mechanism for fostering the development of sustainable infrastructure systems. Sustainability 10: 4463. [CrossRef]

Goyal, Sandeep, Anirudh Agrawal, and Bruno S. Sergi. 2020. Social entrepreneurship for scalable solutions addressing sustainable development goals (SDGs) at BoP in India. Qualitative Research in Organizations and Management: An International Journal 16: 509-29. [CrossRef]

Gujarati, Damodar N., and Dawn C. Porter. 2009. Causality in Economics: The Granger Causality Test. Basic Econometrics, 5th International ed. New York: McGraw-Hill, p. 652.

Hamad, Salaheldin, Muhammad Umar Draz, and Fong-Woon Lai. 2020. The impact of corporate governance and sustainability reporting on integrated reporting: A conceptual framework. SAGE Open 10: 2158244020927431. [CrossRef]

Hassani, Hossein, Xu Huang, Steve MacFeely, and Mohammad Reza Entezarian. 2021. Big data and the united nations sustainable development goals (UN SDGs) at a glance. Big Data and Cognitive Computing 5: 28. [CrossRef]

Ho, Ying-Chin, Wen Bo Wang, and Wen Ling Shieh. 2016. An empirical study of green management and performance in Taiwanese electronics firms. Cogent Business \& Management 3: 1266787.

Huang, Jing-Wen, and Yong-Hui Li. 2018. How resource alignment moderates the relationship between environmental innovation strategy and green innovation performance. Journal of Business $\mathcal{E}$ Industrial Marketing 33: 316-24. [CrossRef]

Hussain, Nazim, Ugo Rigoni, and Elisa Cavezzali. 2018. Does it pay to be sustainable? Looking inside the black box of the relationship between sustainability performance and financial performance. Corporate Social Responsibility and Environmental Management 25: 1198-211. [CrossRef]

Ilg, Patrick. 2019. How to foster green product innovation in an inert sector. Journal of Innovation E Knowledge 4: 129-38.

Inman, R. Anthony, and Kenneth W. Green. 2018. Lean and green combine to impact environmental and operational performance. International Journal of Production Research 56: 4802-18. [CrossRef] 
Jan, Amin, and Maran Marimuthu. 2015. Altman model and bankruptcy profile of Islamic banking industry: A comparative analysis on financial performance. International Journal of Business and Management 10: 110. [CrossRef]

Jan, Amin, Maran Marimuthu, Muhammad Pisol bin Mohd Mat Isa, and Pia A. Albinsson. 2018. Sustainability practices and banks financial performance: A conceptual review from the islamic banking industry in Malaysia. International Journal of Business and Management 13. [CrossRef]

Jan, Amin, Maran Marimuthu, Muhammad Pisol bin Mohd, and Mat Isa. 2019a. The nexus of sustainability practices and financial performance: From the perspective of Islamic banking. Journal of Cleaner Production 228: 703-17. [CrossRef]

Jan, Amin, Maran Marimuthu, Rohail Hassan, and Mehreen Mehreen. 2019b. Sustainable business practices and firm's financial performance in islamic banking: Under the moderating role of islamic corporate governance. Sustainability 11: 6606. [CrossRef]

Jan, Ahmad Ali, Fong-Woon Lai, Muhammad Umar Draz, Muhammad Tahir, Syed Emad Azhar Ali, Muhammad Zahid, and Muhammad Kashif Shad. 2021a. Integrating sustainability practices into islamic corporate governance for sustainable firm performance: From the lens of agency and stakeholder theories. Quality \& Quantity, 1-24. [CrossRef]

Jan, Ahmad Ali, Fong-Woon Lai, and Muhammad Tahir. 2021b. Developing an Islamic Corporate Governance framework to examine sustainability performance in Islamic Banks and Financial Institutions. Journal of Cleaner Production 315: 128099. [CrossRef]

Jan, Amin, Mário Nuno Mata, Pia A. Albinsson, José Moleiro Martins, Rusni Bt Hassan, and Pedro Neves Mata. 2021c. Alignment of islamic banking sustainability indicators with sustainable development goals: Policy recommendations for addressing the COVID-19 pandemic. Sustainability 13: 2607. [CrossRef]

Johl, Satirenjit Kaur, and Md Abu Toha. 2021. The Nexus between Proactive Eco-Innovation and Firm Financial Performance: A Circular Economy Perspective. Sustainability 13: 6253. [CrossRef]

Kääriäinen, Maria, Kristina Mikkonen, and Helvi Kyngäs. 2020. Instrument development based on content analysis. In The Application of Content Analysis in Nursing Science Research. Berlin/Heidelberg: Springer, pp. 85-93.

Karabulut, Tuğba, and Hümeyra Nur Hatipoğlu. 2020. The Effect of Green Product Innovation and Green Process Innovation on Company Performance. International Journal of Commerce and Finance 6: 181-93.

Khaled, Raneem, Heba Ali, and Ehab K. A. Mohamed. 2021. The Sustainable Development Goals and corporate sustainability performance: Mapping, extent and determinants. Journal of Cleaner Production 311: 127599. [CrossRef]

Khan, Huma Warsi, and Moina Athar. 2015. Production of Biodiesel from a Blend of Jatropha Oil and Waste Frying Soybean Oil. Journal of Biofuels 6: 57-61. [CrossRef]

Khan, Parvez Alam, and Satirenjit Kaur Johl. 2019. Nexus of Comprehensive Green Innovation, Environmental Management System-14001-2015 and Firm Performance. Cogent Business \& Management 6: 1691833. [CrossRef]

Khan, Parvez Alam, and Satirenjit Kaur Johl. 2020. Firm Performance from the Lens of Comprehensive Green Innovation and Environmental Management System ISO. Available online: https:/ /videleaf.com/wp-content/uploads/2020/11/Firm-Performancefrom-the-Lens-of-Comprehensive-Green-Innovation-and-Environmental-Management-System-ISO-14001.pdf (accessed on 15 December 2021).

Khan, Huma Warsi, Muhammad Moniruzzaman, Mohamed Mahmoud Elsayed Nasef, and Mohamad Azmi Bustam Khalil. 2020. Ionic liquid assisted cellulose aerogels for cleaning an oil spill. Materials Today: Proceedings 31: 217-20.

Khan, Huma Warsi, Amal A. M. Elgharbawy, Azmi Bustam, and Muhammad Moniruzzaman. 2021a. Design and Selection of Ionic Liquids Via COSMO for Pharmaceuticals and Medicine. In Application of Ionic Liquids in Drug Delivery. Berlin/Heidelberg: Springer, pp. 137-64.

Khan, Huma Warsi, Ambavaram Vijaya Bhaskar Reddy, Mohamad Azmi Bustam, Masahiro Goto, and Muhammad Moniruzzaman. 2021b. Development and optimization of ionic liquid-based emulsion liquid membrane process for efficient recovery of lactic acid from aqueous streams. Biochemical Engineering Journal 176: 108216. [CrossRef]

Khan, Parvez Alam, Satirenjit Kaur Johl, and Shakeb Akhtar. 2021c. Firm Sustainable Development Goals and Firm Financial Performance through the Lens of Green Innovation Practices and Reporting: A Proactive Approach. Journal of Risk and Financial Management 14: 605. [CrossRef]

Khan, Parvez Alam, Satirenjit Kaur Johl, and Shireenjit K. Johl. 2021d. Does adoption of ISO 56002-2019 and green innovation reporting enhance the firm sustainable development goal performance? An emerging paradigm. Business Strategy and the Environment 30: 2922-36. [CrossRef]

Khan, Parvez Alam, Satirenjit Kaur Johl, Pritam Singh, Shireenjit Kaur Johl, Amjad Shamim, Yadi Nurhayadi, N. Wijiharjono, and Ummu S. Al-Azizah. 2021e. Injecting Green Innovation Reporting into Sustainability Reporting. SHS Web of Conferences 124: 05003. [CrossRef]

Khan, Sher Jahan, Puneet Kaur, Fauzia Jabeen, and Amandeep Dhir. 2021f. Green process innovation: Where we are and where we are going. Business Strategy and the Environment 30: 3273-96. [CrossRef]

Kim, Incheol, Christos Pantzalis, and Zhengyi Zhang. 2021. Multinationality and the value of green innovation. Journal of Corporate Finance 69: 101996. [CrossRef]

Kraak, Menno Jan, Britta Ricker, and Yuri Engelhardt. 2018. Challenges of mapping Sustainable Development Goals indicators data. ISPRS International Journal of Geo-Information 7: 482. [CrossRef]

Lassala, Carlos, Maria Orero-Blat, and Samuel Ribeiro-Navarrete. 2021. The financial performance of listed companies in pursuit of the Sustainable Development Goals (SDG). Economic Research-Ekonomska Istraživanja 34: 427-49. [CrossRef] 
Li, Dayuan, Mi Zheng, Cuicui Cao, Xiaohong Chen, Shenggang Ren, and Min Huang. 2017. The impact of legitimacy pressure and corporate profitability on green innovation: Evidence from China top 100. Journal of Cleaner Production 141: 41-49. [CrossRef]

Lin, Woon Leong, Azali Bin Mohamed, Murali Sambasivan, and Nick Yip. 2020. Effect of green innovation strategy on firm-idiosyncratic risk: A competitive action perspective. Business Strategy and the Environment 29: 886-901. [CrossRef]

Lin, Woon Leong, Jo Ann Ho, Murali Sambasivan, Nick Yip, and Azali Bin Mohamed. 2021. Influence of green innovation strategy on brand value: The role of marketing capability and R\&D intensity. Technological Forecasting and Social Change 171: 120946.

Liu, Haiyun, Yue Li, and Dan Song. 2020. An Empirical Study on the Impact of Environmental Tax and Government Innovation Subsidy on Enterprise Green Process Innovation. Preprints, 2020110448. [CrossRef]

Ma, Yuan, Guisheng Hou, and Baogui Xin. 2017. Green process innovation and innovation benefit: The mediating effect of firm image. Sustainability 9: 1778. [CrossRef]

Ma, Yuan, Guisheng Hou, Qiyue Yin, Baogui Xin, and Yajun Pan. 2018. The sources of green management innovation: Does internal efficiency demand pull or external knowledge supply push? Journal of Cleaner Production 202: 582-90. [CrossRef]

Manrique, Sergio, and Carmen-Pilar Martí-Ballester. 2017. Analyzing the effect of corporate environmental performance on corporate financial performance in developed and developing countries. Sustainability 9: 1957. [CrossRef]

Mio, Chiara, Silvia Panfilo, and Benedetta Blundo. 2020. Sustainable development goals and the strategic role of business: A systematic literature review. Business Strategy and the Environment 29: 3220-45. [CrossRef]

Mozas-Moral, Adoración, Enrique Bernal-Jurado, Domingo Fernández-Uclés, and Miguel Jesús Medina-Viruel. 2020. Innovation as the Backbone of Sustainable Development Goals. Sustainability 12: 4747. [CrossRef]

Nguyen, Thi H. H., Mohamed H. Elmagrhi, Collins G. Ntim, and Yue Wu. 2021. Environmental performance, sustainability, governance and financial performance: Evidence from heavily polluting industries in China. Business Strategy and the Environment 30: 2313-31. [CrossRef]

Ogunbiyi, Oyedolapo, Jack Steven Goulding, and Adebayo Oladapo. 2014. An empirical study of the impact of lean construction techniques on sustainable construction in the UK. Construction Innovation 14: 88-107. [CrossRef]

Onyango, Gedion, and Japheth Otieno Ondiek. 2021. Digitalization and Integration of Sustainable Development Goals (SGDs) in Public Organizations in Kenya. Public Organization Review 21: 511-26. [CrossRef]

Ordonez-Ponce, Eduardo, Amelia Clarke, and Adriane MacDonald. 2021. Business contributions to the sustainable development goals through community sustainability partnerships. Sustainability Accounting, Management and Policy Journal 12: 1239-67. [CrossRef]

Oskooei, Behzad Feizi. 2021. Evaluation of Return on Social Media Investment with A Critical Look Over Its Non-Financial Aspect. Turkish Journal of Computer and Mathematics Education (TURCOMAT) 12: 4872-84.

Palčič, Iztok, and Jasna Prester. 2020. Impact of Advanced Manufacturing Technologies on Green Innovation. Sustainability 12: 3499. [CrossRef]

Parmentola, Adele, Antonella Petrillo, Ilaria Tutore, and Fabio De Felice. 2021. Is blockchain able to enhance environmental sustainability? A systematic review and research agenda from the perspective of Sustainable Development Goals (SDGs). Business Strategy and the Environment, 1-24. Available online: https://onlinelibrary.wiley.com/doi/full/10.1002/bse.2882 (accessed on 20 December 2021). [CrossRef]

Pisano, Gary P. 2015. You need an innovation strategy. Harvard Business Review 93: 44-54.

Pradhan, Prajal, Luís Costa, Diego Rybski, Wolfgang Lucht, and Jürgen P. Kropp. 2017. A systematic study of sustainable development goal (SDG) interactions. Earth's Future 5: 1169-79. [CrossRef]

Qi, Guoyou, Zeng Saixing, Tam Chiming, Yin Haitao, and Zou Hailiang. 2013. Stakeholders' influences on corporate green innovation strategy: A case study of manufacturing firms in China. Corporate Social Responsibility and Environmental Management 20: 1-14.

Rehman, Shafique Ur, Sascha Kraus, Syed Asim Shah, Dmitry Khanin, and Raj V. Mahto. 2021. Analyzing the relationship between green innovation and environmental performance in large manufacturing firms. Technological Forecasting and Social Change 163: 120481. [CrossRef]

Ribeiro, Daielly Melina Nassif Mantovani, Flavio Hourneaux Junior, Cristiana Lara Lara Cunha, Patricia Taeko Taeko Kaetsu, Patricia Fernanda Dionizio-Leite, and Celso Machado Junior. 2021. Digital sustainability: How information and communication technologies (ICTs) support sustainable development goals (SDGs) assessment in municipalities. Digital Policy, Regulation and Governance 23: 229-47. [CrossRef]

Rickels, Wilfried, Jonas Dovern, Julia Hoffmann, Martin F. Quaas, Jörn O. Schmidt, and Martin Visbeck. 2016. Indicators for monitoring sustainable development goals: An application to oceanic development in the European Union. Earth's Future 4: $252-67$. [CrossRef]

Rodríguez, Patricia, and Ricardo Chalmeta. 2020. Analysis of the use of Twitter as a tool for the management and communication of the CSR of leading European firms. International Journal of Web Based Communities 16: 180-201. [CrossRef]

Rosati, Francesco, and Lourenço G. D. Faria. 2019. Addressing the SDGs in sustainability reports: The relationship with institutional factors. Journal of Cleaner Production 215: 1312-26. [CrossRef]

Sachs, Jeffrey D., Guido Schmidt-Traub, Mariana Mazzucato, Dirk Messner, Nebojsa Nakicenovic, and Johan Rockström. 2019. Six transformations to achieve the sustainable development goals. Nature Sustainability 2: 805-14. [CrossRef]

Salim, Hengky K., Rory Padfield, Sune Balle Hansen, Shaza Eva Mohamad, Ali Yuzir, Khadijah Syayuti, Mun Hou Tham, and Effie Papargyropoulou. 2018. Global trends in environmental management system and ISO14001 research. Journal of Cleaner Production 170: 645-53. [CrossRef] 
Samad, Nur Syafiqah A., Abdul Samad Abdul-Rahim, Mohd Johari Mohd Yusof, and Katsuya Tanaka. 2020. Impact of Green Building Certificate on Firm's Financial Performance. IOP Conference Series: Earth and Environmental Science 549: 012076. [CrossRef]

Santos, Maria João, and Cristina Silva Bastos. 2020. The adoption of sustainable development goals by large Portuguese companies. Social Responsibility Journal 17: 1079-99. [CrossRef]

Sciarelli, Mauro, Silvia Cosimato, Giovanni Landi, and Francesca Iandolo. 2021. Socially responsible investment strategies for the transition towards sustainable development: The importance of integrating and communicating ESG. The TQM Journal 33: 39-56. [CrossRef]

Shah, Syed Quaid Ali, Fong-Woon Lai, Muhammad Kashif Shad, Zdeňka Konečná, Feybi Ariani Goni, Abdoulmohammad Gholamzadeh Chofreh, and Jiři Jaromír Klemeš. 2021. The Inclusion of Intellectual Capital into the Green Board Committee to Enhance Firm Performance. Sustainability 13: 10849. [CrossRef]

Sharif, Zainon Mat, and Waleed Mohammad Kayed Alhiyasat. 2018. The effect of eco-innovation on organization performance in Jordan industrial estates corporation. In AIP Conference Proceedings. Georgetown: AIP Publishing LLC, vol. 2016, p. 020085.

Song, Wenhao, and Hongyan Yu. 2018. Green innovation strategy and green innovation: The roles of green creativity and green organizational identity. Corporate Social Responsibility and Environmental Management 25: 135-50. [CrossRef]

Stoddard, Isak, Kevin Anderson, Stuart Capstick, Wim Carton, Joanna Depledge, Keri Facer, Clair Gough, Frederic Hache, Claire Hoolohan, and Martin Hultman. 2021. Three Decades of Climate Mitigation: Why Haven't We Bent the Global Emissions Curve? Annual Review of Environment and Resources 46: 653-89. [CrossRef]

Stoll, Christian, and Michael Arthur Mehling. 2020. COVID-19: Clinching the Climate Opportunity. One Earth 3: 400-4. [CrossRef]

Tang, Mingfeng, Grace Walsh, Daniel Lerner, Markus A. Fitza, and Qiaohua Li. 2018. Green innovation, managerial concern and firm performance: An empirical study. Business Strategy and the Environment 27: 39-51. [CrossRef]

Tariq, Adeel, Yuosre F. Badir, Waqas Tariq, and Umair Saeed Bhutta. 2017. Drivers and consequences of green product and process innovation: A systematic review, conceptual framework, and future outlook. Technology in Society 51: 8-23. [CrossRef]

Ting, Ha Chin, Huma Warsi Khan, Ambavaram Vijaya Bhaskar Reddy, Masahiro Goto, and Muhammad Moniruzzaman. 2021. Extraction of salicylic acid from wastewater using ionic liquid-based green emulsion liquid membrane: COSMO-RS prediction and experimental verification. Journal of Molecular Liquids 118280. [CrossRef]

Tjahjadi, Bambang, Noorlailie Soewarno, Hariyati Hariyati, Lina Nasihatun Nafidah, Nanik Kustiningsih, and Viviani Nadyaningrum. 2020. The Role of Green Innovation between Green Market Orientation and Business Performance: Its Implication for Open Innovation. Journal of Open Innovation: Technology, Market, and Complexity 6: 173. [CrossRef]

Toha, Md, Satirenjit Kaur Johl, and Parvez Alam Khan. 2020. Firm's Sustainability and Societal Development from the Lens of Fishbone Eco-Innovation: A Moderating Role of ISO 14001-2015 Environmental Management System. Processes 8: 1152. [CrossRef]

Ullah, Rizwan, Habib Ahmad, Fazal Ur Rehman, and Arshad Fawad. 2021. Green innovation and Sustainable Development Goals in SMEs: The moderating role of government incentives. Journal of Economic and Administrative Sciences. [CrossRef]

Visseren-Hamakers, Ingrid J. 2020. The 18th sustainable development goal. Earth System Governance 3: 100047. [CrossRef]

Wahab, Muhammad Zarunnaim Haji, and Asmadi Mohamed Naim. 2021. The Reviews on Sustainable and Responsible Investment (SRIs) Practices According to Maqasid Shariah and Maslahah Perspectives. ETIKONOMI 20: 397-412. [CrossRef]

Wang, Qiang, and Rui Huang. 2021. The impact of COVID-19 pandemic on sustainable development goals-A survey. Environmental Research 202: 111637. [CrossRef]

Wang, Mingyue, Yingming Li, Junqiang Li, and Zitong Wang. 2021. Green process innovation, green product innovation and its economic performance improvement paths: A survey and structural model. Journal of Environmental Management 297: 113282. [CrossRef]

Weng, Hua-Hung Robin, Ja-Shen Chen, and Pei-Ching Chen. 2015. Effects of green innovation on environmental and corporate performance: A stakeholder perspective. Sustainability 7: 4997-5026. [CrossRef]

Wong, Chee Yew, Christina W. Y. Wong, and Sakun Boon-itt. 2020. Effects of green supply chain integration and green innovation on environmental and cost performance. International Journal of Production Research 58: 4589-609. [CrossRef]

Xiao, Li, and David North. 2018. The role of Technological Business Incubators in supporting business innovation in China: A case of regional adaptability? Entrepreneurship E Regional Development 30: 29-57.

Xie, Xuemei, Jiage Huo, and Hailiang Zou. 2019. Green process innovation, green product innovation, and corporate financial performance: A content analysis method. Journal of Business Research 101: 697-706. [CrossRef]

Xu, Qian, Yujie Lu, Han Lin, and Boying Li. 2021. Does corporate environmental responsibility (CER) affect corporate financial performance? Evidence from the global public construction firms. Journal of Cleaner Production 315: 128131. [CrossRef]

Yadav, Hitesha, Arpan Kumar Kar, and Smita Kashiramka. 2021. How does entrepreneurial orientation and SDG orientation of CEOs evolve before and during a pandemic. Journal of Enterprise Information Management. [CrossRef]

Yi, Yali, Saixing Zeng, Hongquan Chen, and Jonathan Jingsheng Shi. 2021. When Does It Pay to Be Good? A Meta-Analysis of the Relationship between Green Innovation and Financial Performance. IEEE Transactions on Engineering Management. [CrossRef]

Yusuf, Mohammad, Mohamad Sahban Alnarabiji, and Bawadi Abdullah. 2021a. Clean Hydrogen Production Technologies. In Advances in Sustainable Energy. Berlin/Heidelberg: Springer, pp. 159-70.

Yusuf, Mohammad, Ahmad Salam Farooqi, Lau Kok Keong, Klaus Hellgardt, and Bawadi Abdullah. 2021b. Contemporary trends in composite Ni-based catalysts for CO2 reforming of methane. Chemical Engineering Science 229: 116072. [CrossRef] 
Muhammad Zahid, Haseeb Ur Rahman, Wajahat Ali, Musa Khan, Majed Alharthi, Muhammad Imran Qureshi, and Amin Jan. 2020. Boardroom gender diversity: Implications for corporate sustainability disclosures in Malaysia. Journal of Cleaner Production 244: 118683. [CrossRef]

Zehir, Cemal, and Burcu Ozgul. 2020. Environmental orientation and firm performance: The mediation mechanism of green innovation. International Journal of Research in Business and Social Science 9: 13-25. [CrossRef]

Zeisel, Stefan. 2020. Is sustainability a moving target? A methodology for measuring CSR dynamics. Corporate Social Responsibility and Environmental Management 27: 283-96. [CrossRef]

Zhang, Qiang, and Yuan Ma. 2021. The impact of environmental management on firm economic performance: The mediating effect of green innovation and the moderating effect of environmental leadership. Journal of Cleaner Production 292: 126057. [CrossRef]

Zhang, Dayong, Zhao Rong, and Qiang Ji. 2019. Green innovation and firm performance: Evidence from listed companies in China. Resources, Conservation and Recycling 144: 48-55. [CrossRef]

Zhang, Lu, Shuang Zhao, Li Cui, and Lin Wu. 2020a. Exploring Green Innovation Practices: Content Analysis of the Fortune Global 500 Companies. SAGE Open 10: 2158244020914640. [CrossRef]

Zhang, Shengzhong, Yingmin Yu, Qihong Zhu, Chun Martin Qiu, and Aixuan Tian. 2020b. Green innovation mode under carbon tax and innovation subsidy: An evolutionary game analysis for portfolio policies. Sustainability 12: 1385. [CrossRef]

Zhang, Yali, Jun Sun, Zhaojun Yang, and Ying Wang. 2020c. Critical success factors of green innovation: Technology, organization and environment readiness. Journal of Cleaner Production 264: 121701. [CrossRef]

Zhou, Min, Kannan Govindan, and Xiongbiao Xie. 2020. How fairness perceptions, embeddedness, and knowledge sharing drive green innovation in sustainable supply chains: An equity theory and network perspective to achieve sustainable development goals. Journal of Cleaner Production 260: 120950. [CrossRef] 